\title{
Effects of Different Fertilization Patterns on Soil Microbial Biomass C, N in Wax gourd - Pepper Crop Rotation System
}

\author{
Xiao Deng1, 2, a , Chun-Yuan Wu ${ }^{1, b}, Y_{i} L^{1, c}$, Dong-Ming Wu ${ }^{1, d}$, Hua-Dong Tan ${ }^{1, e}$, \\ Qin-Fen $\mathrm{Li}^{1, f^{*}}$, Miao Chen ${ }^{1, \mathrm{~g}^{*}}$ \\ ${ }^{1}$ Environment and Plant Protection Institute, CATAS, Haikou, 571101, China \\ ${ }^{2}$ Experiment Station of Agricultural Environment Scientific Observation in Danzhou, Ministry of \\ Agriculture, P. R. China. Danzhou, 571737, China
}

adx0928@foxmail.com, ${ }^{\mathrm{b}}$ wuchunyuan1981@126.com, ${ }^{\mathrm{c}}$ wish0310@163.com, dwudomy@126.com , e tanhuadong1991@163.com, ${ }^{\dagger}$ qinfenli2005@163.com, ${ }^{9}$ chenm200567@163.com,

* Corresponding author

\begin{abstract}
Keywords: Fertilization pattern, Rotation system, Soil, Microbial biomass C, Microbial biomass $\mathrm{N}$
Abstract. In order to obtain the efficient fertilization patterns for maintaining soil fertility, this research adopted the field experiments to investigate the effects of eight different fertilization patterns on the soil microbial biomass carbon and nitrogen (SMBC, SMBN) in the wax gourd- pepper crop rotation system of Hainan in China. The results showed that the concentrations of SMBC and SMBN were all significantly increased in the treatments of mixed application of chemical fertilizer and organic fertilizer and the treatment of single application of organic fertilizer $(\mathrm{p}<0.05)$. And compared with the treatment of single application of organic fertilizer, only the two treatments of mixed application of $100 \%$ chemical fertilizer and organic fertilizer and mixed application of $75 \%$ chemical fertilizer and organic fertilizer could significantly increase the concentrations of SMBC and SMBN. However, there was no significant difference between the two treatments $(p>0.05)$. It can be concluded that the treatment of mixed application of $75 \%$ chemical fertilizer and organic fertilizer can effectively increase and maintain the SMBC and SMBN, and it is an efficient fertilization pattern to maintain soil fertility in wax gourd- pepper crop rotation system.
\end{abstract}

\section{Introduction}

Soil microbial biomass has a very important role on soil fertility and plant nutrition. It is not only the power of conversion and circulation of soil organic matter and soil nutrient, but also as a reserve warehouse of soil effective nutrients [1]. The influence of fertilization on soil microbial biomass is very great $[2,3]$. And the application of organic fertilizer can significantly increase the concentrations of soil microbial biomass C and N (SMBC, SMBN) [4-6]. The application of chemical fertilizers can also increase soil microbial biomass [7,8], but excessive application of nitrogen, phosphorus and potassium fertilizer can reduce the concentrations of SMBC and SMBN [8]. Hainan belongs to the acidic soil region of south China, and its soil fertility is poor. However, there are few reports about the effects of mixed application of chemical fertilizer and organic fertilizer and reduction application of chemical fertilizer on the microbial biomass in vegetable soil in Hainan. To sum up, this research adopted the field experiments to investigate the effects of eight different fertilization patterns on SMBC and SMBN in wax gourd-pepper crop rotation system in Hainan province. The objective of this study was to obtain the best fertilization pattern of maintaining soil fertility in vegetable field.

\section{Materials and methods}

The test site is located in WenChang experimental field ( $\left.\mathrm{N} 19.32^{\circ}, \mathrm{E} 110.45^{\circ}\right)$ of Chinese academy of tropical agricultural sciences in Hainan Province. The basic physicochemical properties of soil are shown in table 1 . The experiments were conducted with 8 different fertilization patterns, i. e, no fertilizer (CK), single application of chemical fertilizer (T1), single application of organic fertilizer (T2), single application of straw (T3), chemical fertilizer plus straw returning (T4), mixed application 
of $100 \%$ chemical fertilizer and organic fertilizer (T5), mixed application of $75 \%$ chemical fertilizer and organic fertilizer (T6) and mixed application of 50\% chemical fertilizer and organic fertilizer (T7). The randomized block design was applied in the experiment, and each treatment was repeated three times. The planting system of the experiment area was the rotation mode of the wax gourd and pepper. The planting season of wax gourd was from April 2016 to August 2016, and that of pepper was from November 2016 to April 2017. The amounts of fertilizer crop planting season were shown in table 2 in each fertilization pattern. The other management modes in each experiment area were the same in addition to the amount of fertilizer.

Table 1 the basic physicochemical properties of tested soil

\begin{tabular}{|c|c|c|c|c|c|c|c|}
\hline Agrotype & $\mathrm{pH}$ & $\begin{array}{c}\text { Organic matter } \\
{\left[\mathrm{g}^{\circ} \mathrm{kg}^{-1}\right]}\end{array}$ & $\begin{array}{l}\text { Total N } \\
{\left[\mathrm{g}^{\circ} \mathrm{kg}^{-1}\right]}\end{array}$ & 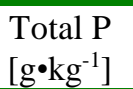 & $\begin{array}{l}\text { Total K } \\
{\left[\mathrm{g} \cdot \mathrm{kg}^{-1}\right]}\end{array}$ & $\begin{array}{l}\text { Available P } \\
{\left[\mathrm{mg}^{\circ} \mathrm{kg}^{-1}\right]}\end{array}$ & $\begin{array}{c}\text { Available K } \\
{\left[\mathrm{mg} \bullet \mathrm{kg}^{-1}\right]}\end{array}$ \\
\hline Laterite & 5.32 & 9.51 & 0.30 & 0.03 & 0.90 & 1.60 & 35.62 \\
\hline
\end{tabular}

Soil samples were collected on August 9, 2016 (the last harvest time of wax gourd) and April 7, 2017 (the last harvest time of the pepper).Soil samples were taken from 0 20 cm tillage layer soil by applying five point sampling method. Samples were stored in plastic bags and taken to the laboratory on the same day. Soil samples were passed through a $2 \mathrm{~mm}$ sieve and then stored in a $4^{\circ} \mathrm{C}$ refrigerator after the plant roots and stones were removed. SMBC and SMBN were analyzed by chloroform fumigation.

Table 2 the experiment design for fertilizer treatment

\begin{tabular}{|c|c|c|c|c|c|c|c|c|}
\hline \multirow{2}{*}{$\begin{array}{l}\text { Fertilization } \\
\text { patterns }\end{array}$} & \multicolumn{3}{|c|}{$\begin{array}{l}\text { Tall fertilizer amount } \\
{\left[\mathrm{kg} \cdot \mathrm{hm}^{-2}\right]}\end{array}$} & \multicolumn{4}{|c|}{$\begin{array}{l}\text { Base manure } \\
{\left[\mathrm{kg} \cdot \mathrm{hm}^{-2}\right]}\end{array}$} & \multirow{2}{*}{$\begin{array}{c}\text { Top } \\
\text { application } \\
{\left[\mathrm{kg} \cdot \mathrm{hm}^{-2}\right]} \\
\begin{array}{c}\text { Compound } \\
\text { fertilizer }\end{array}\end{array}$} \\
\hline & $\mathrm{N}$ & $\mathrm{P}_{2} \mathrm{O}_{5}$ & $\mathrm{~K}_{2} \mathrm{O}$ & $\begin{array}{l}\text { Organic } \\
\text { fertilizer }\end{array}$ & $\begin{array}{l}\text { The straw } \\
\text { returning }\end{array}$ & $\begin{array}{l}\text { Compound } \\
\text { fertilizer }\end{array}$ & $\begin{array}{l}\text { Calcium-magnesia } \\
\text { phosphate fertilizer }\end{array}$ & \\
\hline CK & 0 & 0 & 0 & 0 & 0 & 0 & 0 & 0 \\
\hline $\mathrm{T} 1$ & 315.25 & 274.21 & 315.25 & 0 & 0 & 1250 & 450 & 915 \\
\hline $\mathrm{T} 2$ & 224.10 & 113.40 & 226.80 & 30000 & 0 & 0 & 0 & 0 \\
\hline T3 & 0 & 0 & 0 & 0 & 1800 & 0 & 0 & 0 \\
\hline $\mathrm{T} 4$ & 323.89 & 281.05 & 345.31 & 0 & 1800 & 1250 & 450 & 915 \\
\hline T5 & 539.35 & 387.61 & 542.05 & 30000 & 0 & 1250 & 450 & 915 \\
\hline T6 & 460.74 & 325.26 & 463.44 & 30000 & 0 & 1000 & 338 & 625 \\
\hline $\mathrm{T} 7$ & 382.76 & 247.35 & 385.46 & 30000 & 0 & 834 & 0 & 225 \\
\hline
\end{tabular}

Note: Chemical fertilizer was the calcium-magnesia phosphate fertilizer and the ternary compound fertilizer, in which the base manure was $\mathrm{N}: \mathrm{P}_{2} \mathrm{O}_{5}: \mathrm{K}_{2} \mathrm{O}=15: 15: 15$ and the top application was $\mathrm{N}$ : $\mathrm{P}_{2} \mathrm{O}_{5}: \mathrm{K}_{2} \mathrm{O}=15: 5: 15$. The organic fertilizer was commodity organic fertilizer, which main ingredient was sheep manure. The straw was corn straw.

\section{Results and Discussion}

Fig.1 showed that the concentration of SMBC was the highest in T5 treatment, and that of T6 treatment was the second highest, while that of $\mathrm{CK}$ was the lowest at the last harvest time of wax gourd. The concentrations of SMBC were shown as $\mathrm{T} 5>\mathrm{T} 6>\mathrm{T} 7>\mathrm{T} 2>\mathrm{T} 4>\mathrm{T} 3>\mathrm{T} 1>\mathrm{CK}$ in eight different fertilization patterns. Compared with $\mathrm{CK}$ and $\mathrm{T} 1$, the concentrations of SMBC were all significantly increased in six different fertilization patterns of T2, T3, T4, T5, T6 and T7(p<0.05). Those of T5, T6, T7 and T2 were respectively increased by $286.4 \%, 247.3 \%, 217.4 \%$ and $200.7 \%$ than that of CK treatment. Those of T5, T6, T7 and T2 were respectively increased by $156.4 \%$, $130.5 \%, 110.6 \%$ and $99.5 \%$ than that of T1 treatment. And those of T5 and T6 were significantly increased by $28.5 \%$ and $15.5 \%$ respectively compared with that of $\mathrm{T} 2$ treatment $(\mathrm{p}<0.05)$. However, the differences between T5 and T6 were not significant ( $\mathrm{p}>0.05)$. 


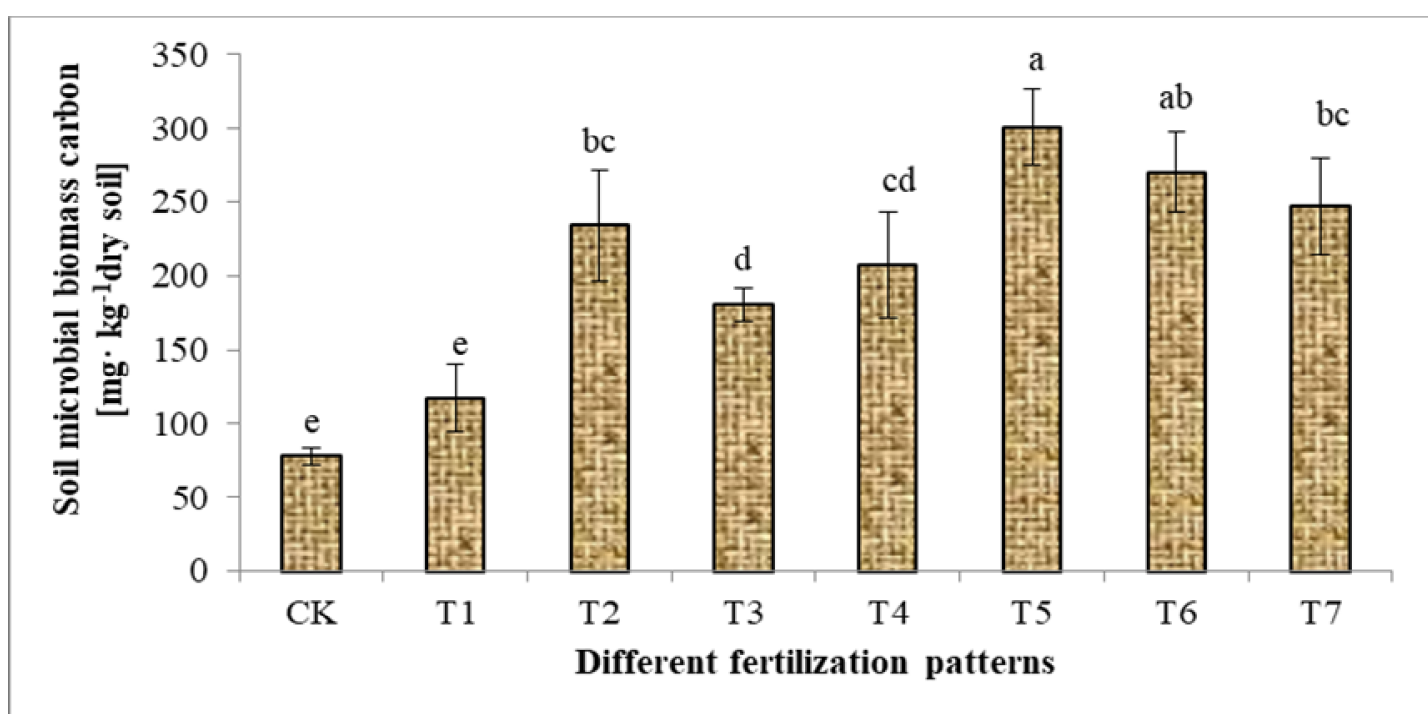

Fig.1 the concentrations of SMBC of different fertilization patterns at wax gourd planting season Note: The different small letters in the figure expressed 5\% significant difference between different treatments. The same letter in the figure indicated no significant difference $(p>0.05)$. And the same below.

Fig. 2 showed that the concentration of SMBC was the highest in T5 treatment, and that of T6 treatment was the second highest, while that of T3 treatment was the lowest at the last harvest time of pepper. The concentrations of SMBC were shown as $\mathrm{T} 5>\mathrm{T} 6>\mathrm{T} 7>\mathrm{T} 2>\mathrm{T} 4>\mathrm{CK}>\mathrm{T} 1>\mathrm{T} 3$ in eight different fertilization patterns. Compared with $\mathrm{CK}$ and $\mathrm{T} 1$, the concentrations of SMBC were all significantly increased in four different fertilization patterns of T2, T5, T6 and T7 ( $<<0.05)$. Those of T5, T6, T7 and T2 were respectively increased by $77.8 \%, 65.1 \%, 50.5 \%$ and $35.5 \%$ than that of CK treatment. And those of T5, T6, T7 and T2 were respectively increased by $108.1 \%, 93.3 \%, 76.2 \%$ and $58.7 \%$ than that of T1 treatment. Those of T5 and T6 were significantly increased by $31.1 \%$ and $21.8 \%$ respectively compared with the T2 treatment $(\mathrm{p}<0.05)$. However, the differences between T5 and T6 were not significant too $(\mathrm{p}>0.05)$.

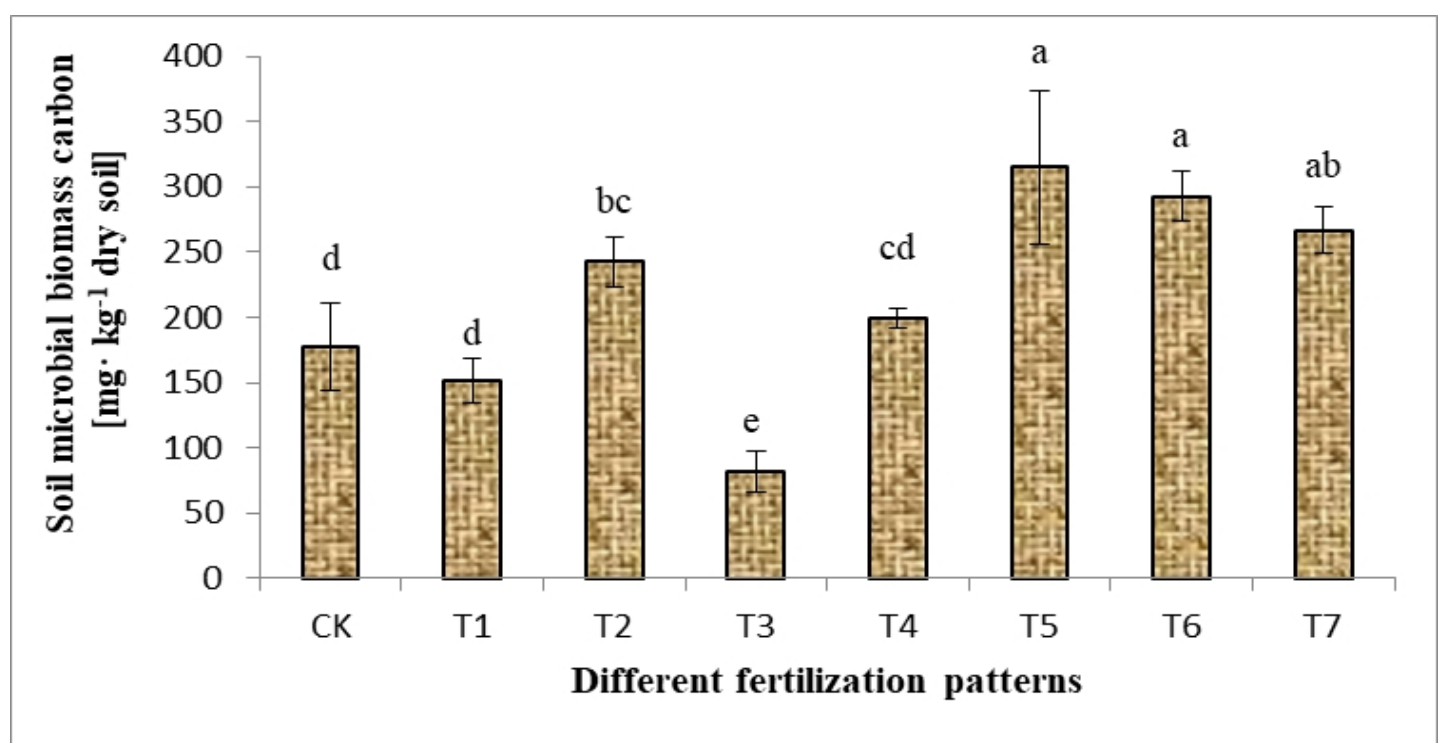

Fig.2 the concentrations of SMBC of different fertilization patterns at pepper planting season

Fig. 3 showed that the SMBN was the highest in T5 treatment, and that of T6 treatment was the second highest, while that of CK treatment was the lowest at the last harvest time of wax gourd. The concentrations of SMBN were shown as T5 > T6 > T7 > T2> T4 > T3 > T1 > CK in eight different fertilization patterns. Compared with $\mathrm{CK}$ and $\mathrm{T} 1$, the concentrations of SMBN were all significantly increased in five different fertilization patterns of T2, T4, T5, T6 and T7 ( $\mathrm{p}<0.05)$. Those of T5, T6, T7 
and T2 were respectively increased by $570.0 \%, 565.5 \%, 397.8 \%$ and $323.2 \%$ than that of treatment. Those of T5, T6, T7 and T2 were respectively increased by $252.7 \%, 250.3 \%, 162.1 \%$ and $122.8 \%$ than that of T1 treatment. And those of T5 and T6 were significantly increased by $58.3 \%$ and $57.2 \%$ respectively compared with that of $\mathrm{T} 2$ treatment $(\mathrm{p}<0.05)$. However, the differences between T5 and T6 were not significant ( $\mathrm{p}>0.05)$.

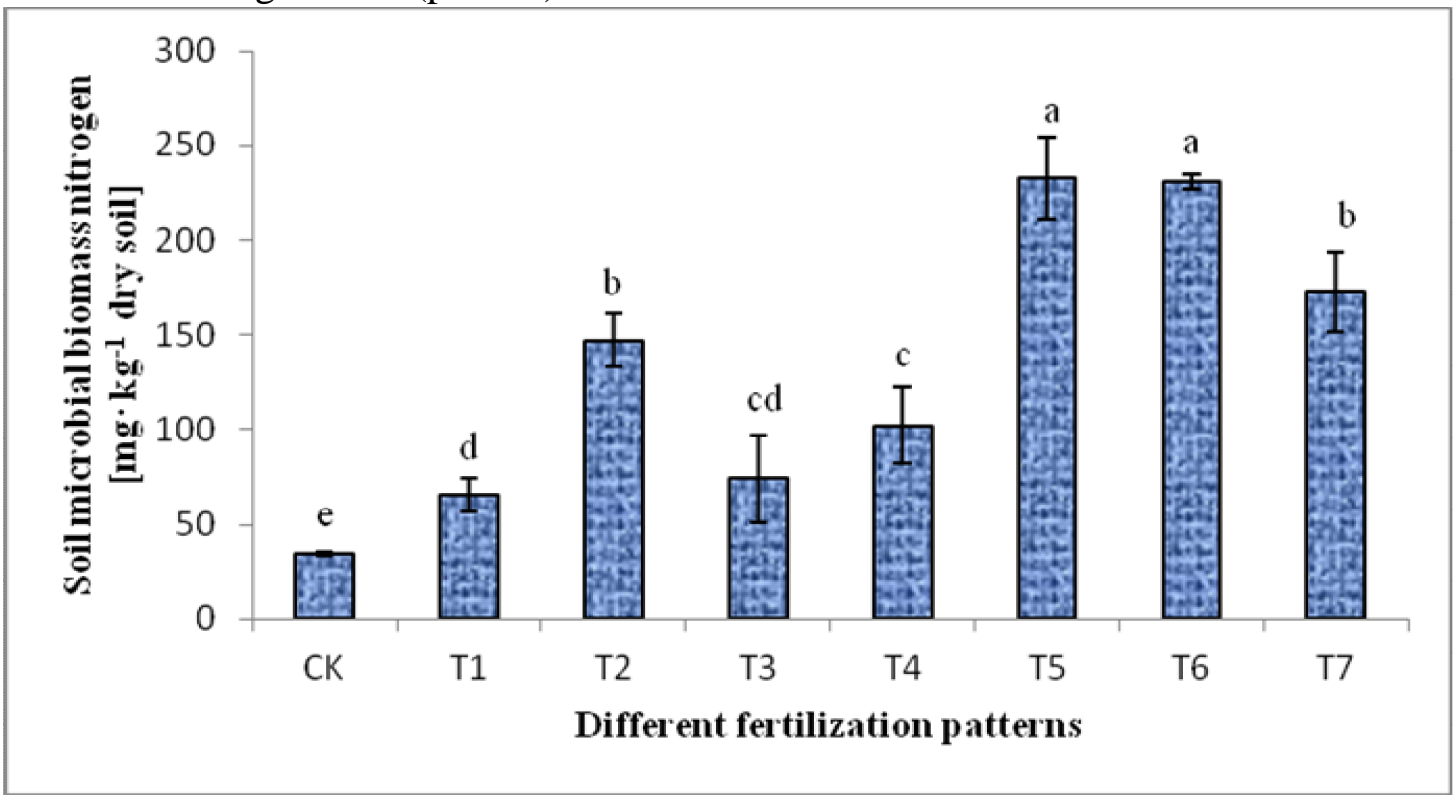

Fig.3 the concentrations of SMBN of different fertilization patterns at wax gourd planting season

Fig.4 showed that the concentrations of SMBN was the highest in T5 treatment, and that of T6 treatment was the second highest, while that of T1 treatment was the lowest at the last harvest time of pepper. The concentrations of SMBN were shown as T5> T6 $>\mathrm{T} 7>\mathrm{T} 2>\mathrm{T} 4>\mathrm{CK}>\mathrm{T} 3>\mathrm{T} 1$ in eight different fertilization patterns. Compared with $\mathrm{CK}$ and $\mathrm{T} 1$, the concentrations of SMBN were all significantly increased in four different fertilization patterns of T2, T5, T6 and T7(p<0.05). Those of T5, T6, T7 and T2 were respectively increased by $136.6 \%, 119.1 \%, 63.8 \%$ and $60.3 \%$ than that of CK treatment. And those of T5, T6, T7 and T2 were respectively increased by $191.9 \%, 170.4 \%, 102.2 \%$ and $97.8 \%$ than that of T1 treatment. Those of T5 and T6 were significantly increased by $47.6 \%$ and $36.7 \%$ respectively compared with that of $\mathrm{T} 2$ treatment $(\mathrm{p}<0.05)$. However, the differences between T5 and T6 were not significant too $(\mathrm{p}>0.05)$.

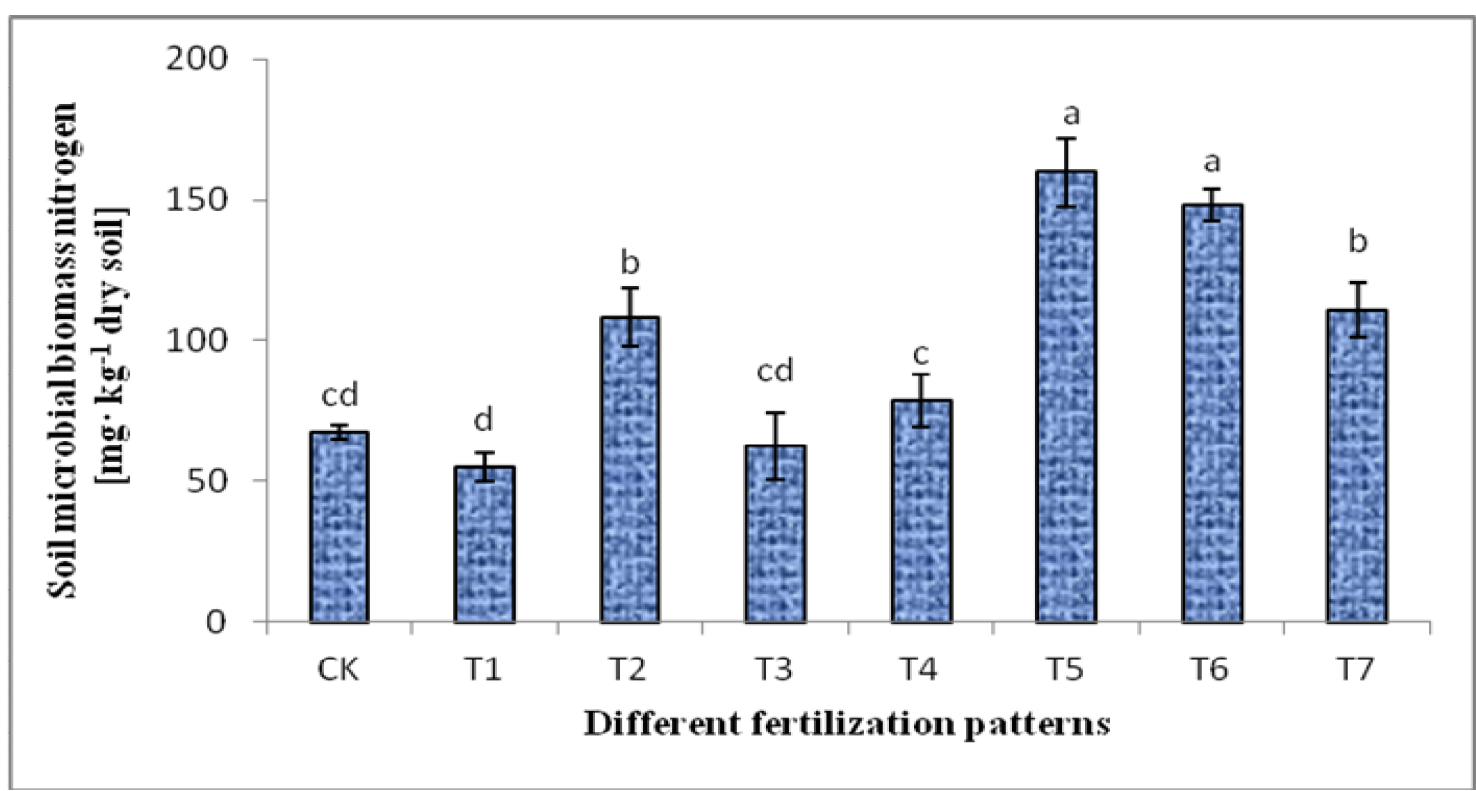

Fig.4 the concentrations of SMBN of different fertilization patterns at pepper planting season 


\section{Conclusions}

The above results indicated that the concentrations of SMBC and SMBN were all significantly increased in the treatments of mixed application of chemical fertilizer and organic fertilizer and single application of organic fertilizer. And compared with the treatment of single application of organic fertilizer, only the two treatments of mixed application of $100 \%$ chemical fertilizer and organic fertilizer and mixed application of $75 \%$ chemical fertilizer and organic fertilizer could significantly increase the concentrations of SMBC and SMBN. However, there was no significant difference between the two treatments. It can be concluded that the treatment of mixed application of $75 \%$ chemical fertilizer and organic fertilizer can effectively increase and maintain the SMBC and SMBN, and it is an efficient fertilization pattern to maintain soil fertility in wax gourd - pepper crop rotation system.

\section{Acknowledgements}

This work was financially supported by the Central Public-interest Scientific Institution Basal Research Fund for Chinese Academy of Tropical Agricultural Sciences Environment and Plant Protection Institute（No.2016hzs1J006, 1630042016004）.

\section{References}

[1] Y.C. Xu, Q.R. Shen and W. Ran. Acta Pedologica Sinica, 2002, Vol.39 (2002), pp89-96.

[2] C. Plaza, D. Hernandez, J.C. Garcia-gil and A. Polo. Soil Biol Biochem, Vol.36 (2004), pp1577-1585.

[3] T. Kautz, S. Wirth and F. Ellmer. EUR J Soil Biol, Vol. 40(2004), pp 87-94.

[4] Y.F. Zang, M.D. Hao, L.Q. Zhang and H.Q. Zhang. Acta Ecologica Sinica, Vol. 35(2015), pp.1445-1451. (In Chinese)

[5] X. X. Ma, L.L. Wang, Q. H. Li, H. Li, S. L. Zhang, B.H. Sun and X.Y. Yang. Acta Ecologica Sinica, Vol.32 (2012), pp 5502-5511. (In Chinese)

[6] E. Witter, A.M. Martnsson and F.V. Garica. Soil Biol Biochem, Vol.25 (1993), pp 659-669.

[7] A.L. Chen, K.R .Wang and X.L. Xie. J. Agro-Environ. Sci., Vol.24 (2005), pp1094-1099.

[8] R.E. Masto, P.K. Chhonkar, D. Singh and A.K. Patra. Soil Biol Biochem, Vol.38 (2006), pp1577-1582. 